\title{
Intrarenal production of B-cell survival factors in human lupus nephritis
}

\author{
Matthias A Neusser ${ }^{1}$, Maja T Lindenmeyer ${ }^{1,2}$, Ilka Edenhofer ${ }^{1,2}$, Stefanie Gaiser ${ }^{1,2}$, \\ Matthias Kretzler ${ }^{3}$, Heinz Regele ${ }^{4}$, Stephan Segerer ${ }^{1,5,6}$ and Clemens D Cohen ${ }^{1,2,6}$ \\ ${ }^{1}$ Division of Nephrology, Department of Internal Medicine, University Hospital, Zurich, Switzerland; \\ ${ }^{2}$ Institute of Physiology with Zurich Center of Integrative Human Physiology, University of Zurich, Zurich, \\ Switzerland; ${ }^{3}$ Department of Medicine, University of Michigan, Ann Arbor, Michigan, USA $;{ }^{4}$ Clinical Institute \\ of Pathology, University of Vienna, Vienna, Austria and ${ }^{5}$ Institute of Anatomy, University of Zurich, Zurich, \\ Switzerland
}

\begin{abstract}
The B-cell survival factors APRIL and BLyS are important for B-cell maturation and activation and contribute to human autoimmune diseases. Interference with B-cell function by targeting these molecules is currently being investigated in large clinical trials for systemic lupus erythematosus. The local expression patterns of APRIL and BLyS have not been investigated in detail in kidneys with lupus nephritis. We studied the mRNA expression of APRIL, BLyS, and the corresponding receptors BCMA, TACI, and BAFF-R in microdissected human biopsies with proliferative lupus nephritis $(n=25)$ and compared it with pretransplant biopsies of living donors $(n=9)$. APRIL and BLyS mRNA levels were significantly higher in glomeruli of patients with proliferative lupus nephritis (12- and 30-fold, respectively). Tubulointerstitial expression of APRIL, BLyS, BCMA, and TACl was also significantly elevated. To localize the respective proteins in the kidney, APRIL, BLyS, and BAFF-R were studied by immunohistochemistry in renal biopsies with proliferative $(n=21)$ or membranous $(n=8)$ lupus nephritis. APRIL was prominently expressed in glomeruli with proliferative, but not membranous, lupus nephritis. The staining pattern was consistent with mesangial cells. A prominent accumulation of CD68-positive cells was present in glomeruli in association with APRIL expression. APRIL, BLyS, and BAFF-R were also expressed in interstitial inflammatory cell accumulation. This is the first study, which details local expression of APRIL and BLyS in glomeruli and tubulointerstitium of human proliferative lupus nephritis. This information might help define intrarenal effects of APRIL and BLyS inhibition in human lupus nephritis.

Modern Pathology (2011) 24, 98-107; doi:10.1038/modpathol.2010.184; published online 1 October 2010
\end{abstract}

Keywords: APRIL; BAFF-R; BLyS; gene expression; lupus nephritis

Renal involvement in systemic lupus erythematosus is a severe complication with major impact on morbidity and mortality. ${ }^{1}$ Immunosuppressive therapy with cyclophosphamide or mycophenolate mofetil has been shown to improve the renal outcome of lupus nephritis considerably. ${ }^{1,2}$ Although a mainstay of therapy, these treatments are associated with serious side effects. ${ }^{1,2}$ Therefore, more specific therapeutic

Correspondence: Dr CD Cohen, MD, Division of Nephrology, Institute of Physiology, Winterthurerstr. 190, Zurich CH-8057, Switzerland.

E-mail: clemens.cohen@access.uzh.ch

${ }^{6}$ These authors contributed equally to this work.

Received 18 May 2010; revised 27 July 2010; accepted 28 July 2010; published online 1 October 2010 approaches to this systemic disease are being intensively evaluated.

B cells are considered to be involved in lupus nephritis, particularly as a source for nephritogenic auto-antibodies. ${ }^{3}$ The B-cell survival factors belonging to the tumor necrosis factor (TNF) superfamily, ie, TNFSF13/APRIL (member 13/ a proliferation inducing ligand) and TNFSF13B/BLyS (member 13B/B-lymphocyte stimulator, or BAFF for B-cell activating factor), have a pivotal role in B-cell biology. APRIL and BLyS are expressed by monocytes, macrophages, dendritic cells, T cells, B cells, but also non-hematopoietic cells, eg, cancer cells., ${ }^{4,5}$ The three known receptors of the mentioned ligands are TNFRSF13C/BAFF-R (tumor necrosis factor receptor superfamily, member $13 \mathrm{C} / \mathrm{B}$-cell activating factor receptor), TNFRSF17/BCMA (member 17/B-cell 
maturation antigen), and TNFRSF13B/TACI (member 13B/transmembrane activator and CAML interactor). BAFF-R has a strong selectivity for BLyS, whereas BCMA has a higher affinity for APRIL, and TACI binds both ligands equally. ${ }^{4}$ APRIL may also bind to heparan sulfate proteoglycans. ${ }^{6,7}$ The receptors for BAFF and APRIL are mainly expressed on B cells. ${ }^{4}$ In addition to the well established role in B-cell survival, these factors exert functions on different subsets of cells, eg, $\mathrm{T}$ cells ${ }^{4,5}$ and monocytes. ${ }^{8,9}$

In systemic lupus erythematosus, APRIL and BLyS have been shown to be involved in the B-cellmediated pathology. ${ }^{10}$ Transgenic mice with constitutive overexpression of BLyS show lupus-like features. ${ }^{11,12}$ In contrast, APRIL-transgenic mice manifest only subtle abnormalities. ${ }^{13}$ In lupus mouse models, circulating BLyS levels were found to be elevated $^{12}$ and interventions into the APRIL/BLyS system ameliorated proteinuria and renal inflammation. ${ }^{12,14,15}$ Consistently in human systemic lupus erythematosus, serum as well as blood mRNA levels of APRIL and BLyS were found to be elevated. ${ }^{16-18}$ Although depleting B cells by an anti-CD20 antibody, eg, by rituximab, surprisingly failed to show significant benefit in patients with renal and non-renal systemic lupus erythematosus, ${ }^{19}$ phase II/III clinical trials investigating the blockade of the APRIL/ BLyS system in systemic lupus erythematosus have been initiated (LBSLO2/99 NCT00071487 and NCT 00583362; BLISS-76/NCT00410384 and BLISS-52/ NCT00424476; NCT00624338) and promising results have been reported. ${ }^{20,21}$

Although systemic therapies targeting APRIL and BLyS have reached the stage of clinical trials, no detailed data on local renal expression of this system in human proliferative lupus nephritis are currently available. We hypothesized that a complex expression of factors in this local APRIL/BLyS system might be involved in renal tissue injury and might even be a future therapeutic target. Therefore, to better understand the tissue-specific responses in interventional trials in systemic lupus erythematosus, we localized and quantified members of this system in human biopsies with proliferative lupus nephritis.

\section{Materials and methods}

\section{Renal Biopsies and mRNA Analysis}

Human renal biopsy specimens were procured in an international multicenter study, the European Renal cDNA Bank-Kröner-Fresenius biopsy bank (see Acknowledgments). All biopsy cores were obtained for routine diagnostic purposes (ie, light microscopy, immunofluorescence, and electron microscopy) and reviewed by experienced renal pathologists. The characteristics of all patients are shown in Table 1. We used the ISN/RPS ${ }^{22}$ classification, which divides proliferative glomerular lesions into class III
Table 1 Clinical and histological characteristics of the samples used for real-time RT-PCR

\begin{tabular}{|c|c|c|c|c|c|}
\hline Sample & Histology & Age & Sex & Creatinine & Proteinuria \\
\hline SLE 1 GA & III & 37 & $\mathrm{~F}$ & $79(0.9)$ & 2.40 \\
\hline SLE 2 & III & 22 & $\mathrm{~F}$ & $70(0.8)$ & 3.20 \\
\hline SLE 3 & III & 50 & $\mathrm{~F}$ & $106(1.2)$ & 0.80 \\
\hline SLE 4 & III & NA & NA & $106(1.2)$ & 2.10 \\
\hline SLE 5 & III & 37 & NA & $106(1.2)$ & 1.78 \\
\hline SLE 6 & III & 29 & $\mathrm{~F}$ & $65(0.7)$ & NA \\
\hline SLE 7 & III & 28 & $\mathrm{~F}$ & $90(1.0)$ & 1.00 \\
\hline SLE 8 & III & 19 & $\mathrm{~F}$ & $73(0.8)$ & 13.00 \\
\hline SLE 9 & IV & 35 & $\mathrm{~F}$ & $62(0.7)$ & 2.00 \\
\hline SLE 10 & IV & 29 & $\mathrm{~F}$ & 97 (1.1) & 1.00 \\
\hline SLE 11 & IV & 46 & $\mathrm{~F}$ & $282(3.2)$ & 10.60 \\
\hline SLE 12 & IV & 45 & $\mathrm{~F}$ & $141(1.6)$ & 4.20 \\
\hline SLE 13 & IV & 72 & M & $114(1.3)$ & 1.75 \\
\hline SLE 14 & IV & 42 & $\mathrm{~F}$ & $141(1.6)$ & 0.71 \\
\hline SLE 15 & IV & 46 & $\mathrm{M}$ & $97(1.1)$ & 2.10 \\
\hline SLE 16 & IV & 51 & $\mathrm{~F}$ & $69(0.8)$ & 5.00 \\
\hline SLE 17 GA & IV & 43 & $\mathrm{~F}$ & $86(1.0)$ & 4.00 \\
\hline SLE 18 & IV & 28 & $\mathrm{~F}$ & $264(3.0)$ & 4.00 \\
\hline SLE 19 & IV & 17 & $\mathrm{~F}$ & $194(2.2)$ & 8.80 \\
\hline SLE 20 & IV & 26 & $\mathrm{~F}$ & $158(1.8)$ & 1.70 \\
\hline SLE 21 & IV & 42 & $\mathrm{~F}$ & $79(0.9)$ & 2.90 \\
\hline SLE 22 & IV & 19 & $\mathrm{~F}$ & $158(1.8)$ & 3.30 \\
\hline SLE 23TA & IV & 31 & $\mathrm{M}$ & 125 (1.4) & 8.00 \\
\hline SLE 24 GA & IV & 18 & $\mathrm{~F}$ & 141 (1.6) & 3.50 \\
\hline SLE 25 GA & IV & 51 & $\mathrm{~F}$ & $79(0.9)$ & 0.50 \\
\hline LD 1 GA & Normal & 35 & $\mathrm{~F}$ & $<88(1.0)$ & $<0.2$ \\
\hline LD 2 GA & Normal & 56 & $\mathrm{~F}$ & $<88(1.0)$ & $<0.2$ \\
\hline LD 3 GA & Normal & 41 & M & $<88(1.0)$ & $<0.2$ \\
\hline LD 4 GA & Normal & 62 & $\mathrm{M}$ & $<88(1.0)$ & $<0.2$ \\
\hline LD 5 & Normal & 27 & $\mathrm{M}$ & $<88(1.0)$ & $<0.2$ \\
\hline LD 6 & Normal & NA & NA & $<88(1.0)$ & $<0.2$ \\
\hline LD 7 TA & Normal & 58 & $\mathrm{~F}$ & $<88(1.0)$ & $<0.2$ \\
\hline LD 8 TA & Normal & 56 & $\mathrm{~F}$ & $<88(1.0)$ & $<0.2$ \\
\hline LD 9 TA & Normal & 70 & $\mathrm{~F}$ & $<88(1.0)$ & $<0.2$ \\
\hline
\end{tabular}

NA, not available; LD, living donor; RT-PCR, reverse transcriptasePCR; SLE, systemic lupus erythematosus.

If not specifically indicated, the samples were used for both glomerular (GA) and tubulointerstitial (TA) analyses. Histology is given according to the ISN/RPS classification. ${ }^{22}$ Patients' age is given in years, serum creatinine in $\mu \mathrm{mol} / \mathrm{l}$ (mg per $100 \mathrm{ml}$ ), proteinuria in g/day.

(focal disease, ie, $<50 \%$ of glomeruli affected) and IV (diffuse disease, ie, more than $50 \%$ of glomeruli affected); membranous lupus nephritis is categorized as class V. Real-time reverse transcriptase-PCR (realtime RT-PCR) was performed on biopsy specimen from patients with systemic lupus erythematosus and lupus nephritis ISN/RPS ${ }^{22}$ III or IV with active lesions ( $n=24$ for APRIL and BLyS in glomeruli, $n=21$ for APRIL, BLyS and their receptors in the tubulointerstitium) and control subjects (living donors, $n=6$ for glomerular and $n=5$ for tubular analyses).

After informed consent and with approval of the local ethics committees, a cortical tissue specimen was separated from one of the newly obtained, unfixed biopsy cores. This sample was transferred to RNase inhibitor and microdissected into glomerular and tubular specimen. RNA isolation and real-time RT-PCR was performed as previously reported. ${ }^{23}$ Pre-developed TaqMan reagents were used for human TNFSF13, TNFSF13B, TNFRSF13B, TNFRSF13C, 
TNFRSF17, and the reference genes 18S rRNA and GAPDH (Applied Biosystems, Darmstadt, Germany). The expression of candidate genes was normalized to both reference genes giving similar results. All fold-changes shown are normalized to GAPDH. The mRNA expression was analyzed by standard curve quantification.

\section{Renal Biopsies and Immunohistochemistry}

Immunohistochemistry was performed on biopsies not used for the mRNA analyses. Included were biopsies from patients with proliferative (type IV, $n=21$ ) or membranous (type $\mathrm{V}, n=8$ ) lupus nephritis. Immunohistochemistry was performed as previously described. ${ }^{24,25}$ In brief, dewaxed and rehydrated renal biopsy sections were incubated in $3 \%$ hydrogen peroxide to block endogenous peroxidases. The Avidin/Biotin blocking Kit (Vector, Burlingame, CA, USA) was used to block endogenous biotin. An autoclave oven was used for heatbased antigen retrieval in Antigen retrieval solution (Vector). Incubation with the primary antibodies was performed for $1 \mathrm{~h}$ in $10 \%$ non-fat dry milk. Incubation with biotinylated secondary antibodies (Vector) for $30 \mathrm{~min}$ was followed by the ABC reagent (Vector). $3^{\prime} 3^{\prime}$ Diaminobenzidine (Sigma, Taufkirchen, Germany) with metal enhancement served as detection system. As primary antibodies we used the following: polyclonal serum against APRIL (US Biological, Swampscott, MA, USA ${ }^{26}$ ), monoclonal BLyS antibody (Alexis Biochemicals, Lausen, Switzerland ${ }^{27,28}$ ), and monoclonal BAFF-R antibody (Clone 11C1, Alexis Biochemicals ${ }^{27}$ ). The monoclonal mouse anti-CD68 antibody (Clone PG-M1, DAKO Germany, Hamburg) has previously been used extensively in formalin-fixed, paraffin-embedded renal biopsies. ${ }^{29}$ Negative controls were performed on sections of allograft nephrectomies and human tonsils with a non-immune rabbit serum.

\section{Cell Culture}

Human mesangial cells ${ }^{30}$ were cultured as previously reported. Except for controls they were stimulated with the indicated reagents and concentrations ( $n=3$ or $n=4$ wells for each condition): universal type 1 interferon (IFN)- $\alpha(1000 \mathrm{U} / \mathrm{ml}$; PBL InterferonSource, NJ, USA), recombinant human interferon IFN- $\beta(1000 \mathrm{U} / \mathrm{ml}$; R\&D Systems, Abingdon, UK), recombinant human IFN- $\gamma(1000 \mathrm{U} / \mathrm{ml}$; R\&D Systems), recombinant human interleukin (IL)2 ( $5 \mathrm{ng} / \mathrm{ml}$; R\&D Systems) and recombinant human TNF- $\alpha(25 \mathrm{ng} / \mathrm{ml}$; R\&D Systems). Also, a combination of the three IFNs as well as a combination of IFN- $\gamma$ and TNF- $\alpha$ in the above concentrations was used. Cells were harvested at 12 and $24 \mathrm{~h}$. Total cellular RNA was extracted using the Qiagen RNeasy kit (Qiagen, Hombrechtikon, Switzerland).
The mRNA expression was analyzed by real-time RT-PCR.

\section{Statistics}

Experimental data are given as mean \pm s.d. Statistical analysis was performed using Kruskal-Wallis test, Mann-Whitney U-test, and Pearson's correlation test (SPSS 17.0). P-values $<0.05$ were considered to indicate statistically significant differences.

\section{Results}

Glomerular and Tubulointerstitial APRIL and BLyS mRNA Levels are Increased in Proliferative Lupus Nephritis

Real-time RT-PCR was performed to quantify the mRNA expression of APRIL, BLyS, BAFF-R, BCMA, and TACI in microdissected human renal biopsies. The clinical and morphological data of the patients included in the study are summarized in Table 1. APRIL and BLyS mRNA expression was significantly higher in microdissected glomeruli from patients with proliferative lupus nephritis as compared with controls (fold-induction of APRIL: $11.6 \pm 22.4, P<0.05$ and BLyS: $29.8 \pm 47.1, P<0.01$, Figure $1 \mathrm{a}$ and $\mathrm{b})$. In the tubulointerstitial compartment, an induction of APRIL and BLyS mRNAs was also found in lupus nephritis compared with controls (fold-induction of APRIL: 12.6 \pm 25.3 , $P<0.01$ and BLyS: $57.7 \pm 93.9, P<0.01$; Figure 1c and $d$ ). Subgroup analysis revealed that the above results were also true if ISN/RPS III and IV classes were studied separately (data not shown). Real-time RT-PCR for the receptors, BAFF-R, BCMA, and TACI, revealed glomerular mRNA expression, which was too low to be quantified. In the tubulointerstitium, mRNA levels for TACI and BCMA were significantly higher in lupus nephritis compared with controls (fold-induction 109.0 $\pm 305.4, P<0.05$; $135.8 \pm 332.1, P<0.01$ respectively, Figure $1 \mathrm{e}$ and f). BAFF-R mRNA showed very low expression levels in lupus nephritis and controls and no significant induction (not illustrated). Again subgroup analysis revealed that the above results were found in both ISN/RPS III and IV lupus nephritis (data not shown).

Glomerular expression of APRIL mRNA correlated positively with glomerular expression of BLyS mRNA $(r=0.93, P<0.01)$. It also showed positive correlation with tubulointerstitial expression of APRIL $(r=0.86, P<0.01)$, BLyS $(r=0.93, P<0.01)$, BCMA $(r=0.94, P<0.0 .1)$, and TACI mRNA $(r=$ 0.92, $P<0.01)$. Glomerular expression of BLyS mRNA also correlated with tubulointerstitial expression of APRIL $(r=0.97, P<0.01)$, BLyS $(r=0.96$, $P<0.01)$, BCMA $(r=0.89, \quad P<0.01)$, and TACI mRNA ( $r=0.82, P<0.01$ ). No significant correlation was found between APRIL or BLyS mRNAs with serum creatinine, proteinuria, or ISN/RPS stage in either glomeruli or tubulointerstitium, respectively. 

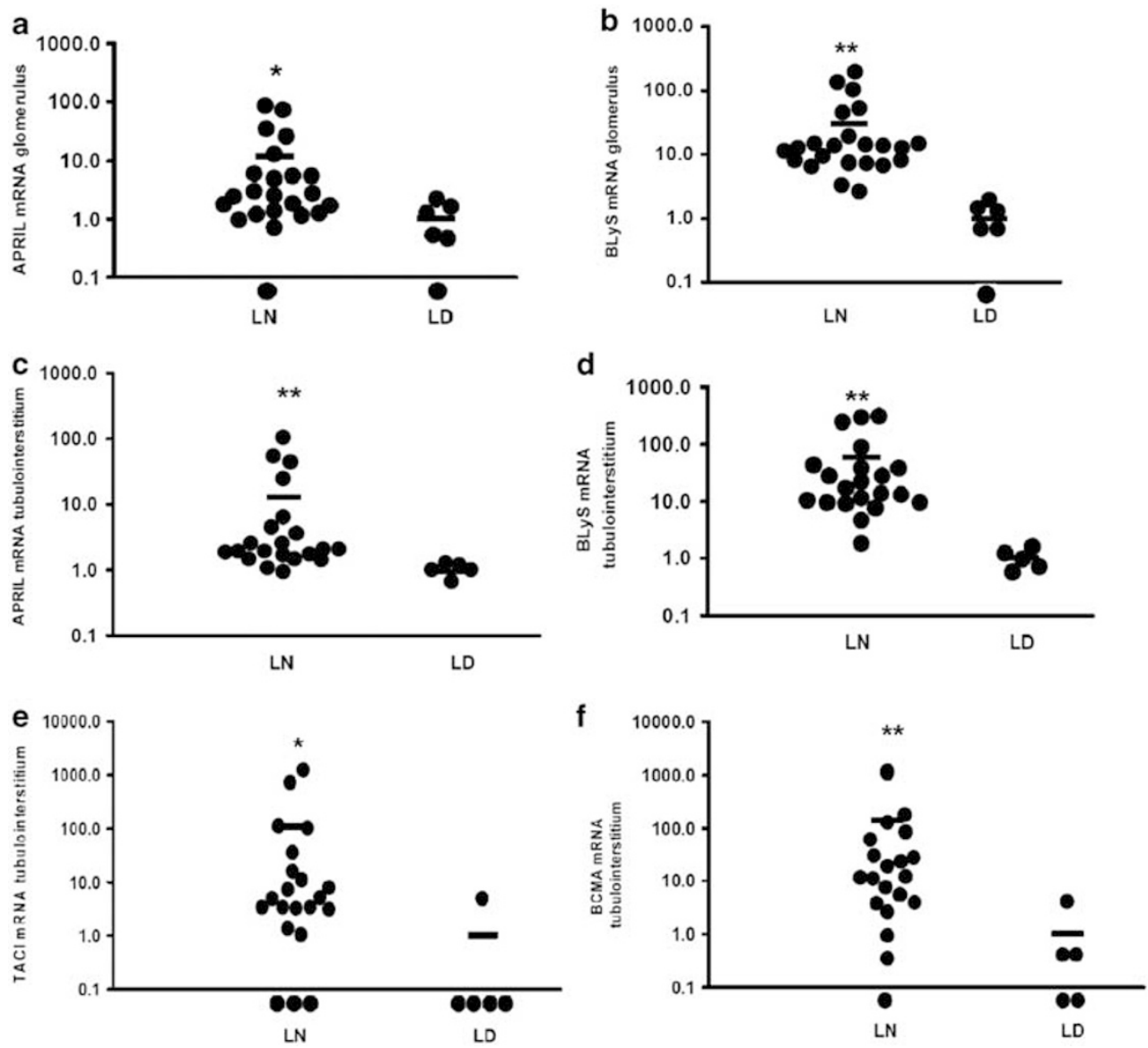

Figure 1 Expression of mRNA for APRIL and BLyS and their receptors in human proliferative lupus nephritis and control tissue. APRIL and BLyS mRNA are increased in glomeruli $(\mathbf{a}, \mathbf{b})$ as well as the tubulointerstitial compartment (c, d) in human proliferative lupus nephritis (LN) compared with living donors (LD). The mRNA levels for the receptors TACI and BCMA are increased in the tubulointerstitial compartment of kidneys with lupus nephritis (e, f). BAFF-R mRNA showed very low constitutive expression with no clear induction in disease (not shown). ${ }^{*}$ and ${ }^{* *}$ indicate $P<0.05$ and $P<0.01$, respectively.

Glomerular Expression of APRIL Protein in Proliferative, but not in Membranous Lupus Nephritis

To further describe the morphological distribution of APRIL, we used immunohistochemistry on formalinfixed, paraffin-embedded renal biopsies. Allograft nephrectomies and human tonsils were used to establish the immunohistochemical application of a commercial antibody (Figure 2). A very reliable staining pattern was established with a heat-based antigen retrieval (Figure 2a and c). Controls using an isotypematched immunoglobulin were negative (Figure 2b and d). Immunohistochemisty was then performed on a total of 29 renal biopsies from patients with either proliferative (ISN/RPS IV, $n=21$ ) or membranous (ISN/RPS V, $n=8$ ) lupus nephritis.

The biopsies from patients with proliferative lupus nephritis demonstrated a prominent mesangial expression of APRIL (Figure 3a, b and e). The APRIL staining was particularly prominent at the vascular pole (Figure 3c and e). Eleven of the 21 biopsies also demonstrated a mesangial APRIL expression. Only one biopsy was completely negative in glomeruli. Furthermore, APRIL was found to be present in parietal epithelial cells in 14 of 21 biopsies. As expected, APRIL was also positive in inflammatory cells of glomeruli and the tubulointerstitium in lupus nephritis (Figure $3 \mathrm{~d}$ ). ${ }^{5}$ An accumulation of CD68-positive monocytes/macrophages was present in glomeruli with prominent expression of APRIL (Figure 3e and f).

In the renal biopsies from patients with membranous lupus nephritis, the glomeruli were most commonly negative for APRIL (Figure 2e and f). Five of the eight biopsies demonstrated APRILpositive cells at the vascular pole. Within the glomerular tuft, six biopsies were negative or demonstrated faint staining. Only two biopsies demonstrated a mesangial pattern. APRIL-positive parietal epithelial cells were only present in one out of eight biopsies with membranous lupus nephritis. In contrast, BLyS protein was only detected in inflammatory infiltrates in the tubulointerstitium in selected cases (not illustrated).

Expression of BAFF-R was restricted to a small population of infiltrating cells. These cells were 
a

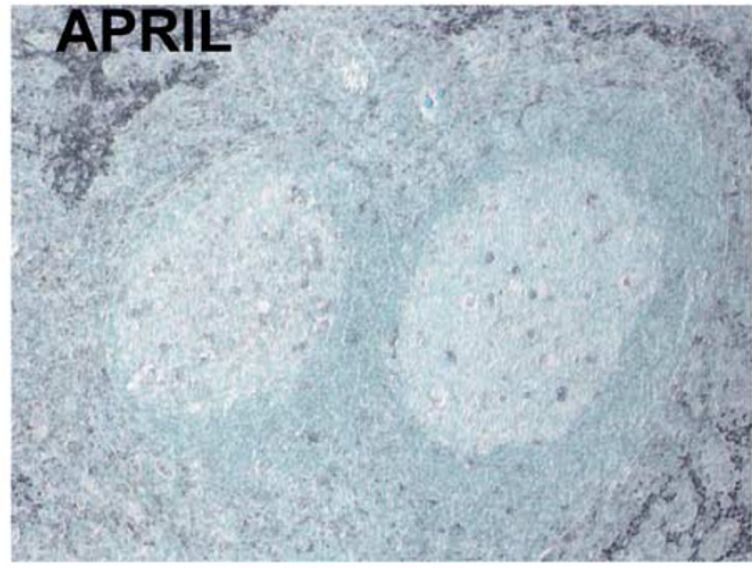

C

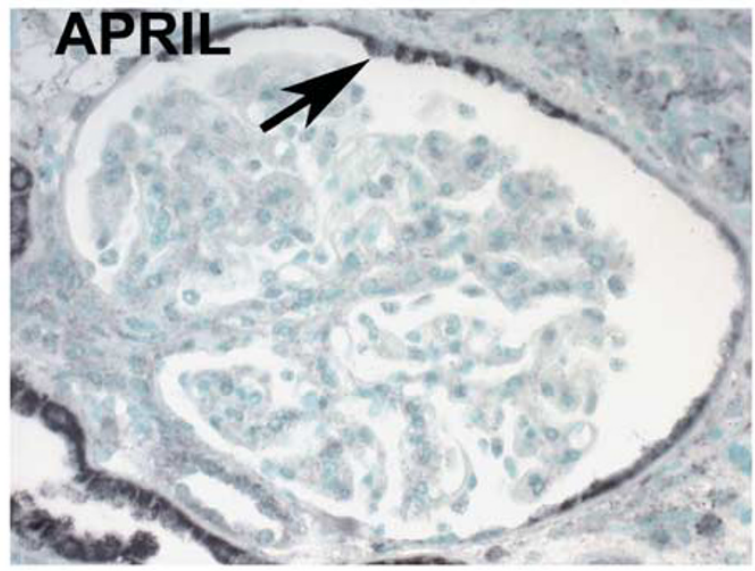

e

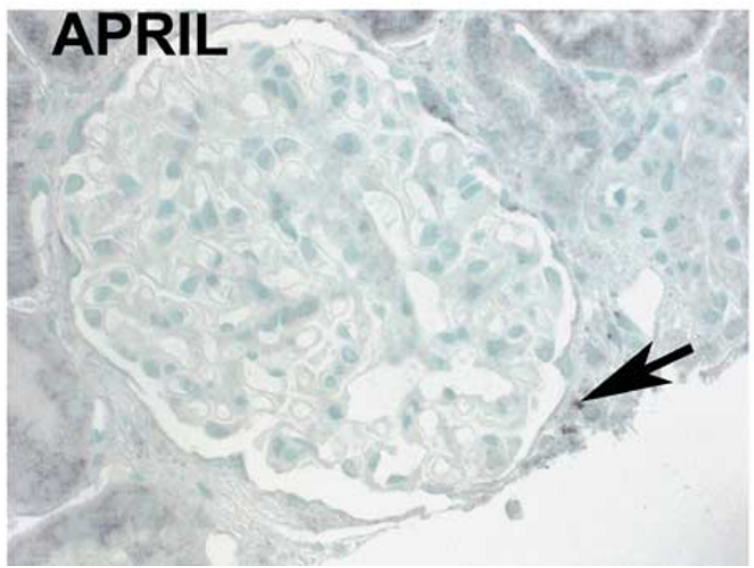

b IgG

\section{d $\lg G$}

\section{' CD68}

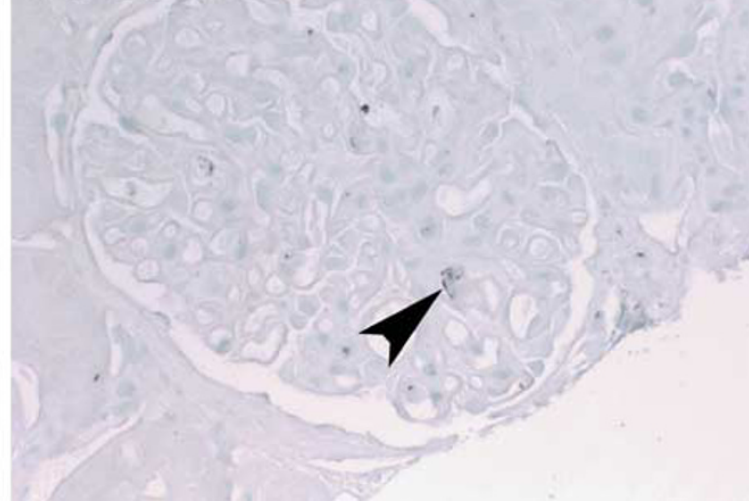

Figure 2 Establishment of the anti-APRIL antibody for immunohistochemistry and expression in membranous lupus nephritis. Immunohistochemistry was performed with a polyclonal antibody against human APRIL (a, c, e), an isotype control immunoglobulin $(\mathbf{b}, \mathbf{d})$, or CD68 (f) on human tonsil $(\mathbf{a}, \mathbf{b})$, an allograft nephrectomy (c, d) and a biopsy with membranous lupus nephritis (e, f). In the allograft nephrectomy, prominent expression was found in parietal epithelial cells (arrow) in some glomeruli, but no significant expression within the glomerular tuft. (b, d) Note the absence of positive color product in the controls. (e, f) In this biopsy with membranous lupus nephritis, APRIL staining within the glomerular tuft was absent. The arrow in panel e highlights an APRIL-positive cell within the tubulointerstitium. Scattered CD68-positive monocytes/macrophages were present within glomerular capillaries (arrowhead in f).

particularly seen in nodular inflammatory cell accumulation consistent with B cells (Figure 3h, compared with the consecutive expression of APRIL in Figure 3g). Expression by intrinsic renal cells was not detected.

\section{Cell Culture}

To further examine the mesangial expression of APRIL seen by immunohistochemistry, we studied APRIL expression in vitro. In cultured mesangial 
cells, very low basal mRNA expression for APRIL was found (mean $C_{\mathrm{t}}$-value: $36 \pm 1 ; n=3$ ). ${ }^{30}$ No rise in APRIL mRNA was seen under proinflammatory stimulation with IFN- $\alpha,-\beta,-\gamma$, IL-2, and human TNF- $\alpha$ (data not shown).

\section{Discussion}

In this study, we provide the first detailed data on intrarenal expression of APRIL, BLyS, and their receptors in human lupus nephritis. These data are particularly important, as interventions into the APRIL/BLyS system are currently evaluated in several multicenter studies aimed primarily at systemic effects of B-cell interference in systemic lupus erythematosus. ${ }^{20,21}$

Data on intrarenal expression patterns of the B-cell survival factors are scarce. A local infiltration of the kidneys by APRIL- and BLyS-positive B cells was recently described. ${ }^{31}$ This study lacked detailed description of the biopsy material used. Therefore, in this study, we used a number of biopsies with well-described morphological groups of lupus nephritis. In our study, we demonstrate a strong increase of APRIL mRNA by real-time RT-PCR in microdissected glomeruli from patients with proliferative lupus nephritis. The corresponding receptors in this renal compartment remain to be elucidated. Because of the low level of mRNA expression we were not able to clarify by real-time RT-PCR which receptor might be targeted in the glomerular injury process. In the tubulointerstitium, we found mRNA for both ligands as well as the receptors TACI and BCMA induced. Additionally, we found very low expression of BAFF-R mRNA, which is in line with the localization to a minor population of BAFF-R-positive cells infiltrating the interstitium described below.

For immunohistological confirmation studies, we paid special attention to glomeruli as lupus
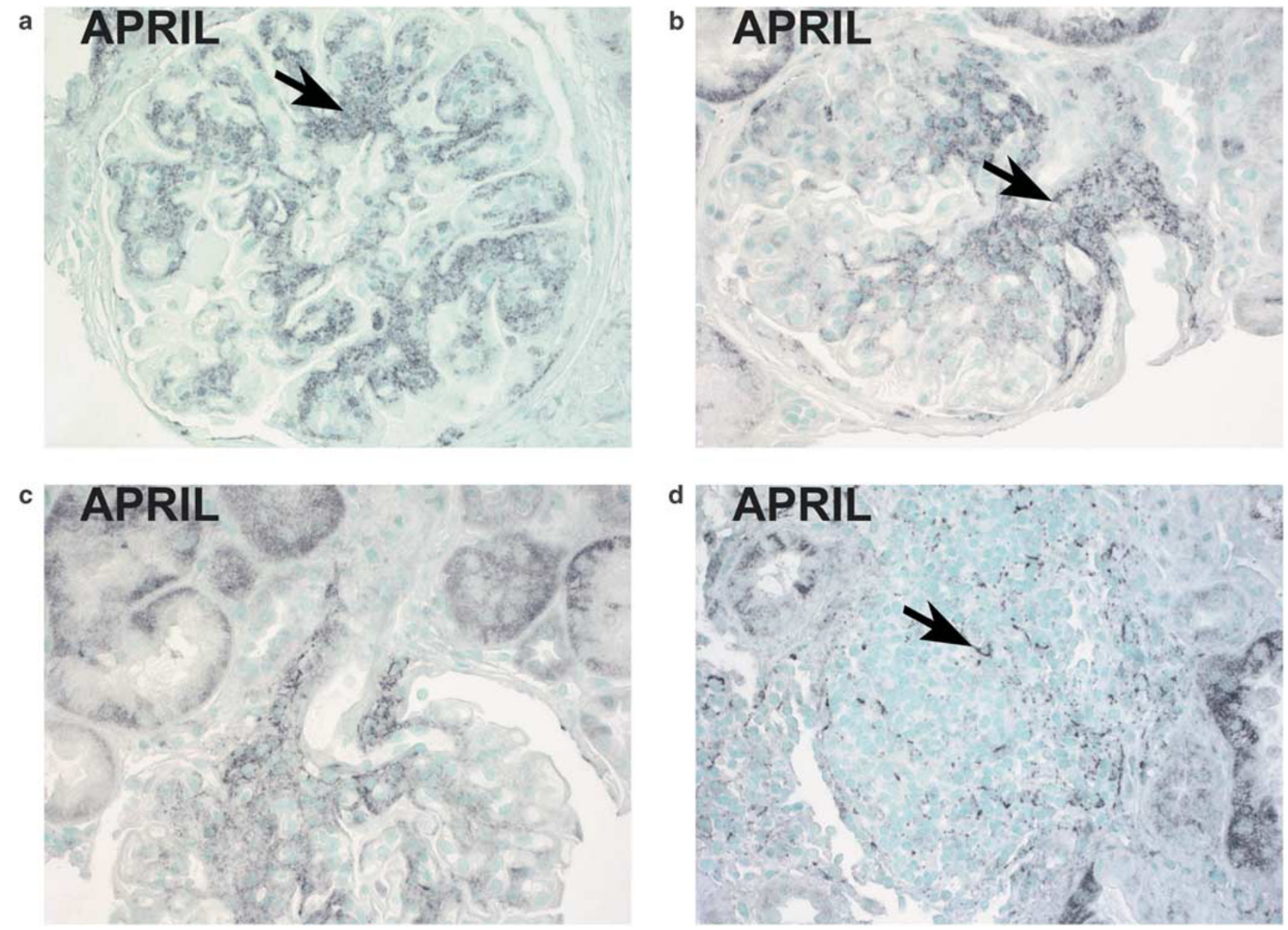

Figure 3 Localization of APRIL in proliferative lupus nephritis. Immunohistochemistry was performed with a polyclonal antibody against human APRIL (a-e, g), a monoclonal antibody against CD68 (f) and a monoclonal antibody against BAFF-R (h) on renal biopsies with proliferative lupus nephritis. Prominent expression of APRIL in a mesangial pattern is illustrated in a (arrow), with some positivity along peripheral capillary walls. Positive staining at the vascular pole was also commonly detectable (arrow in b, also c, e). Positivity of interstitial infiltrating cells is shown in $\mathbf{d}$ (arrow). (e, f) Consecutive staining for CD68 shows prominent accumulation of macrophages in the glomerular tuft (some illustrated by arrows in $\mathbf{f}$ ). (g, h) Consecutive sections stained for APRIL and BAFF-R are illustrated. Some interstitial infiltrating cells are positive for APRIL (arrow in g). Only a small population of interstitial infiltrating cells, consistent with B cells, demonstrated expression of BAFF-R (h). 

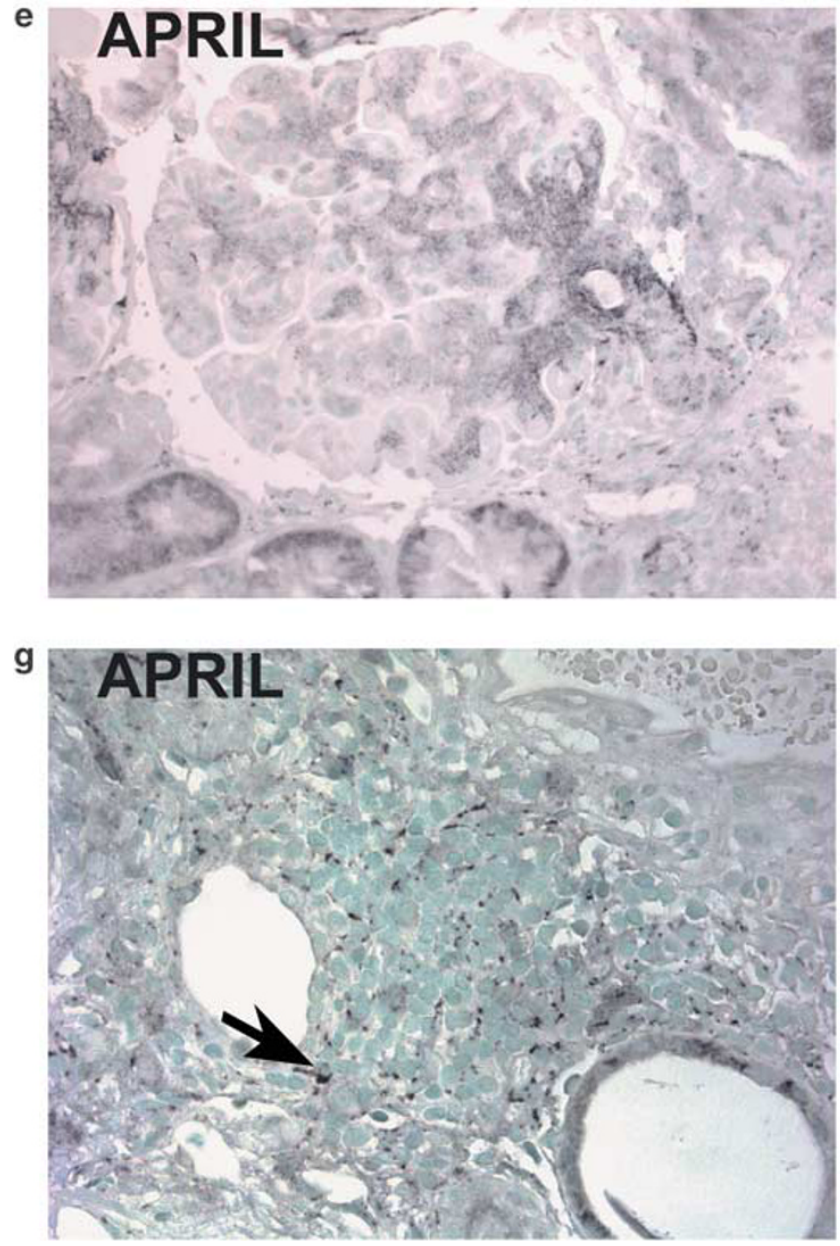

Figure 3 Continued.

nephritis presents initially as a glomerular disease and the ISN/RPS classification is based on glomerular rather than tubulointerstitial pathology. ${ }^{22}$ Surprisingly, besides the expected expression of APRIL in inflammatory cells, the morphological pattern of distribution was consistent with autochthonous mesangial cells. This is in contrast with Chu et al., ${ }^{31}$ who described renal APRIL expression solely in infiltrating B lymphocytes. As it is unclear, which classes of lupus nephritis were included in the study by Chu et al., ${ }^{31}$ and as we could not consistently detect APRIL in mesangial cells of membranous lupus nephritis, our finding of APRIL in mesangial cells may indeed indicate a rather specific finding in proliferative lupus nephritis. However, our results of mesangial cells expressing APRIL are in line with the well-documented expression of APRIL by cells other than those of the hematopoietic lineage, e.g., non-hematopoietic, non-immune cells in solid tumors, ${ }^{32,33}$ and in other cells such as osteoclasts. ${ }^{5}$

In the tubulointerstitium, APRIL could be localized to infiltrating inflammatory cells, in line with the report by Chu et al. ${ }^{31}$ Also, BLyS could
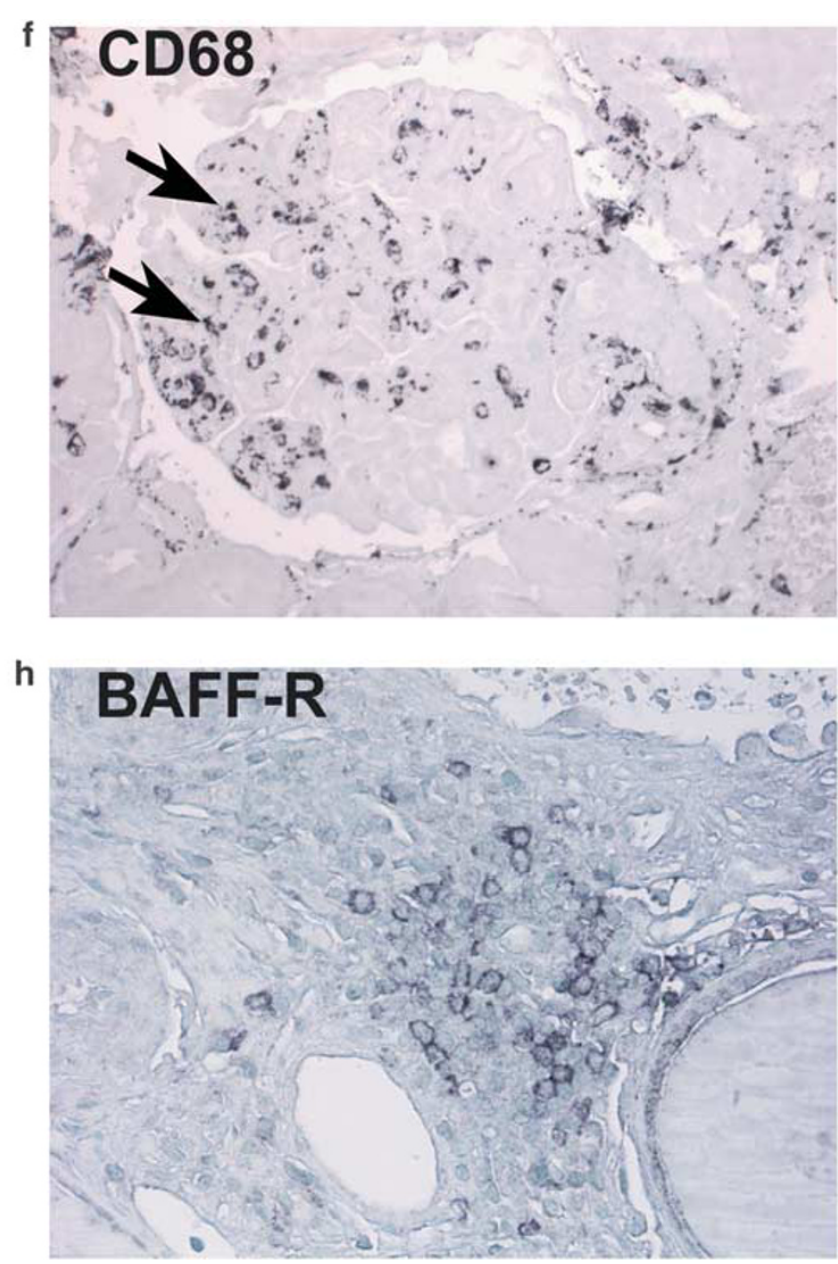

be localized by us to inflammatory infiltrates in the tubulointerstitium in selected cases. Although we detected by immunohistochemistry a more pronounced signal for APRIL than BLyS, we found strong positive correlations between mRNA levels of APRIL and BLyS. The corresponding BAFF-R was tracked by us to a small population of interstitial infiltrating cells. In sum, the B-cell survival factors are involved locally in glomeruli and tubulointerstitium of lupus nephritis and, surprisingly, intrinsic renal cells rather than merely immigrating inflammatory cells expressed APRIL in the glomerulus.

In agreement with our data on a local role for APRIL and BLyS in lupus nephritis, components of this system have been described locally in target organs in various other autoimmune diseases: In human multiple sclerosis, APRIL protein was found in the cerebrospinal fluid, ${ }^{34}$ BLyS mRNA was detected in cerebral lesions, and BLyS protein is expressed by astrocytes in multiple sclerosis lesions. ${ }^{35}$ As BAFF-R-positive inflammatory cells are seen near BLyS-positive astrocytes, BLyS has been speculated to support plasma cell-mediated 
inflammation. ${ }^{35}$ This local expression of BLyS and BAFF-R in multiple sclerosis is somewhat reminiscent of that described by us in lupus nephritis for APRIL in mesangial cells and inflammatory cells in their vicinity. In human Sjögren's syndrome, immunohistochemical evidence for BLyS production in epithelial cells of salivary glands exists. ${ }^{28,36} \mathrm{BLyS}-$ positive monocytes, ${ }^{37} \mathrm{~B},{ }^{38}$ and $\mathrm{T}^{37}$ lymphocytes as well as BAFF-R-positive B lymphocytes ${ }^{38}$ infiltrating salivary glands in Sjögren's syndrome have been demonstrated, similar to the BLyS-/BAFF-R-positive interstitial cell infiltrate seen in lupus nephritis. In human rheumatoid arthritis, different cells seem to express the B-cell survival factors: one immunohistochemical study found APRIL in germinal center positive synovitis in CD83-positive dendritic cells, whereas BLyS was derived from CD68-positive monocytes/macrophages. ${ }^{39}$ Other studies on human rheumatoid arthritis described APRIL in mononuclear cells and lymphocytes infiltrating the synovial area. ${ }^{40}$ BLyS and BAFF-R protein were also described to be expressed by synovial monocytes, as well as $\mathrm{T}$ and $\mathrm{B}$ lymphocytes. ${ }^{27}$ Consistently, in lupus nephritis we found BLyS and BAFF-R in a small population of inflammatory cells in the interstitium. In human rheumatoid arthritis, APRIL and BLyS are locally expressed by intrinsic fibroblast-like synoviocytes. ${ }^{27,40,41}$ The expression of APRIL by local fibroblast-like synoviocytes in rheumatoid arthritis is somewhat similar to the APRIL expression by mesangial cells in lupus nephritis. Interestingly, we could show low basal expression levels of APRIL mRNA in cultured mesangial cells. ${ }^{30}$ However, we could not demonstrate increased APRIL mRNA expression by this cell line under proinflammatory stimulation. As the glomerular APRIL expression is only found in ISN/ RPS III and IV lupus nephritis, but not in ISN/RPS V, we may have failed to sufficiently mimic the specific glomerular milieu of proinflammatory mediators or stimulation by immune complexes.

Based on the above descriptive data on local expression of APRIL and BLyS and the data mentioned in other autoimmunopathies several hypotheses can be formulated. APRIL has been shown to downregulate apoptosis, e.g., in lymphoma B cells. ${ }^{42,43}$ Mesangial cell-derived APRIL may promote survival and proliferation in an autocrine or paracrine, e.g., proteoglycan-receptor-mediated, manner leading to increased glomerular cellularity. ${ }^{6,44,45}$ On the other hand, the expression of BLyS and BAFF-R in inflammatory cells of the interstitium in lupus nephritis, as described by us, may help sustain autocrine $\mathrm{B}^{31}$ and $\mathrm{T}$ lymphocytemediated inflammation in the tubulointerstitial compartment of kidneys with lupus nephritis. In the glomerular compartment, few T cells, even fewer $\mathrm{B}$ cells and no dendritic cells are typically present. $^{29,46,47}$ Thus, macrophages, which we and others $^{48}$ could identify in glomeruli with lupus nephritis, may have a prominent role. Chang et al. ${ }^{9}$ show in vitro that BLyS stimulation of TACI expressing monocytes led to the enhancement of their survival and their activation. Willen et al. ${ }^{8}$ show in in vitro experiments that APRIL binds to monocytes via proteoglycans and TACI, mediating different effects such as monocyte adhesion. APRIL and BLyS may thus be potential ligands of monocytes infiltrating lupus nephritis glomeruli. In support of this hypothesis, we found monocytic infiltrates in close proximity to APRIL expressing mesangial cells.

In summary, our detailed analyses of the intrarenal expression of APRIL, BLyS, and their receptors add the glomerular mesangium to the list of cellular compartments capable of local ligand expression. As in arthritis, the role of this local production in the course of disease has still to be elucidated. However, our data might help interpret the upcoming results of APRIL/BLyS interference in autoimmunopathies with renal manifestations such as lupus nephritis.

\section{Acknowledgements}

We thank all participating centers of the European Renal cDNA Bank-Kröner-Fresenius biopsy bank (ERCB-KFB) and their patients for their cooperation. Active members at the time of the study: Clemens David Cohen, Holger Schmid, Michael Fischereder, Lutz Weber, Matthias Kretzler, Detlef Schlöndorff, Munich/Zurich/AnnArbor/New York; Jean Daniel Sraer, Pierre Ronco, Paris; Maria Pia Rastaldi, Giuseppe D’Amico, Milano; Peter Doran, Hugh Brady, Dublin; Detlev Mönks, Christoph Wanner, Würzburg; Andrew Rees, Aberdeen; Frank Strutz, Gerhard Anton Müller, Göttingen; Peter Mertens, Jürgen Floege, Aachen; Norbert Braun, Teut Risler, Tübingen; Loreto Gesualdo, Francesco Paolo Schena, Bari; Jens Gerth, Gunter Wolf, Jena; Rainer Oberbauer, Dontscho Kerjaschki, Vienna; Bernhard Banas, Bernhard Krämer, Regensburg; Moin Saleem, Bristol; Rudolf Wüthrich, Zurich; Walter Samtleben, Munich; Harm Peters, Hans-Hellmut Neumayer, Berlin; Mohamed Daha, Leiden; Katrin Ivens, Bernd Grabensee, Düsseldorf; Francisco Mampaso (deceased), Madrid; Jun Oh, Franz Schaefer, Martin Zeier, Hermann-Joseph Gröne, Heidelberg; Peter Gross, Dresden; Giancarlo Tonolo; Sassari; Vladimir Tesar, Prague; Harald Rupprecht, Bayreuth; Hermann Pavenstädt, Münster; Hans-Peter Marti, Bern. CDC is supported by the Swiss National Science Foundation (32-122439/1) and the Else KrönerFresenius Foundation (A62/04), SS by the University of Zurich (Forschungskredit) and the Swiss National Science Foundation (32003B_129710); and MK by the Alliance for Lupus Research.

\section{Disclosure/conflict of interest}

The authors declare no conflict of interest. 


\section{References}

1 Bhat P, Radhakrishnan J. B lymphocytes and lupus nephritis: new insights into pathogenesis and targeted therapies. Kidney Int 2008;73:261-268.

2 Ginzler EM, Aranow C. Mycophenolate mofetil in lupus nephritis. Lupus 2005;14:59-64.

3 Clatworthy MR, Smith KG. B cells in glomerulonephritis: focus on lupus nephritis. Semin Immunopathol 2007;29:337-353.

4 Mackay F, Schneider P. Cracking the BAFF code. Nat Rev Immunol 2009;9:491-502.

5 Kimberley FC, Medema JP, Hahne M. APRIL in B-cell Malignancies and Autoimmunity. Results Probl Cell Differ 2009;49:161-182.

6 Ingold K, Zumsteg A, Tardivel A, et al. Identification of proteoglycans as the APRIL-specific binding partners. J Exp Med 2005;201:1375-1383.

7 Hendriks J, Planelles L, de Jong-Odding J, et al. Heparan sulfate proteoglycan binding promotes APRIL-induced tumor cell proliferation. Cell Death Differ 2005;12:637-648.

8 Willen D. Identifizierung, Charakterisierung, und funktionelle Analyse der Bindungspartner von APRIL und TACI auf Monocyten und Dendritischen Zellen. Inaugural Dissertation thesis, Ruprecht-Karls-Universität Heidelberg 2006.

9 Chang SK, Arendt BK, Darce JR, Wu X, Jelinek DF. A role for BLyS in the activation of innate immune cells. Blood 2006;108:2687-2694.

10 Cancro MP, D’Cruz DP, Khamashta MA. The role of B lymphocyte stimulator (BLyS) in systemic lupus erythematosus. J Clin Invest 2009;119:1066-1073.

11 Mackay F, Woodcock SA, Lawton P, et al. Mice transgenic for BAFF develop lymphocytic disorders along with autoimmune manifestations. J Exp Med 1999;190:1697-1710.

12 Gross JA, Johnston J, Mudri S, et al. TACI and BCMA are receptors for a TNF homologue implicated in B-cell autoimmune disease. Nature 2000;404:995-999.

13 Stein JV, Lopez-Fraga M, Elustondo FA, et al. APRIL modulates B and T cell immunity. J Clin Invest 2002; 109:1587-1598.

14 Kayagaki N, Yan M, Seshasayee D, et al. BAFF/BLyS receptor 3 binds the $B$ cell survival factor BAFF ligand through a discrete surface loop and promotes processing of NF-kappaB2. Immunity 2002;17:515-524.

15 Ramanujam M, Wang X, Huang W, et al. Similarities and differences between selective and nonselective BAFF blockade in murine SLE. J Clin Invest 2006;116:724-734.

16 Morel J, Roubille C, Planelles L, et al. Serum levels of tumour necrosis factor family members a proliferationinducing ligand (APRIL) and B lymphocyte stimulator (BLyS) are inversely correlated in systemic lupus erythematosus. Ann Rheum Dis 2009;68: 997-1002.

17 Collins CE, Gavin AL, Migone TS, et al. B lymphocyte stimulator (BLyS) isoforms in systemic lupus erythematosus: disease activity correlates better with blood leukocyte BLyS mRNA levels than with plasma BLyS protein levels. Arthritis research \& therapy 2006;8:R6.

18 Stohl W, Metyas S, Tan SM, et al. Inverse association between circulating APRIL levels and serological and clinical disease activity in patients with systemic lupus erythematosus. Ann Rheum Dis 2004;63: 1096-1103.
19 Bosch X. Inflammation: Rituximab in ANCA vasculitis and lupus: bittersweet results. Nat Rev Nephrol 2010;6:137-139.

20 Navarra S, Guzman R, Gallacher A, et al. Belimumab, a BLyS-specific inhibitor, reduced disease activity, flares and prednisone use in patients with active SLE: efficacy and safety results from the Phase 3 BLISS-52 study. Arthritis Rheum 2009;60:3859-3861.

21 Merrill JT, Furie R, Wallace DJ, et al. 4 year experience of Belimumab,a fully human monoclonal antibody, in the treatment of systemic lupus erythematosus (SLE). Ann Rheum Dis 2009;68:254.

22 Weening JJ, D'Agati VD, Schwartz MM, et al. The classification of glomerulonephritis in systemic lupus erythematosus revisited. Kidney Int 2004;65: 521-530.

23 Cohen CD, Frach K, Schlondorff D, Kretzler M. Quantitative gene expression analysis in renal biopsies: a novel protocol for a high-throughput multicenter application. Kidney Int 2002;61:133-140.

24 Heller F, Lindenmeyer MT, Cohen CD, et al. The contribution of B cells to renal interstitial inflammation. Am J Pathol 2007;170:457-468.

25 Segerer S, Banas B, Wornle M, et al. CXCR3 is involved in tubulointerstitial injury in human glomerulonephritis. Am J Pathol 2004;164:635-649.

26 Pelekanou V, Kampa M, Kafousi M, et al. Expression of TNF-superfamily members BAFF and APRIL in breast cancer: immunohistochemical study in 52 invasive ductal breast carcinomas. BMC Cancer 2008;8:76.

27 Nakajima K, Itoh K, Nagatani K, et al. Expression of BAFF and BAFF-R in the synovial tissue of patients with rheumatoid arthritis. Scand J Rheumatol 2007;36: 365-372.

28 Groom J, Kalled SL, Cutler AH, et al. Association of BAFF/BLyS overexpression and altered B cell differentiation with Sjogren's syndrome. J Clin Invest 2002;109:59-68.

29 Segerer S, Heller F, Lindenmeyer MT, et al. Compartment specific expression of dendritic cell markers in human glomerulonephritis. Kidney Int 2008;74:37-46.

30 Banas B, Wornle M, Merkle M, et al. Binding of the chemokine SLC/CCL21 to its receptor CCR7 increases adhesive properties of human mesangial cells. Kidney Int 2004;66:2256-2263.

31 Chu VT, Enghard P, Schurer S, et al. Systemic activation of the immune system induces aberrant BAFF and APRIL expression in B cells in patients with systemic lupus erythematosus. Arthritis Rheum 2009;60:2083-2093.

32 Mhawech-Fauceglia P, Kaya G, Sauter G, et al. The source of APRIL up-regulation in human solid tumor lesions. J Leukoc Biol 2006;80:697-704.

33 Hahne M, Kataoka T, Schroter M, et al. APRIL, a new ligand of the tumor necrosis factor family, stimulates tumor cell growth. J Exp Med 1998;188:1185-1190.

34 Thangarajh M, Masterman T, Rot U, et al. Increased levels of APRIL (a proliferation-inducing ligand) mRNA in multiple sclerosis. J Neuroimmunol 2005;167:210-214.

35 Krumbholz M, Theil D, Derfuss T, et al. BAFF is produced by astrocytes and up-regulated in multiple sclerosis lesions and primary central nervous system lymphoma. J Exp Med 2005;201:195-200.

36 Szodoray P, Jellestad S, Teague MO, Jonsson R. Attenuated apoptosis of B cell activating factorexpressing cells in primary Sjogren's syndrome. Lab 
Invest; a J Techn Methods and Pathol 2003;83: 357-365.

37 Lavie F, Miceli-Richard C, Quillard J, et al. Expression of BAFF (BLyS) in T cells infiltrating labial salivary glands from patients with Sjogren's syndrome. J Pathol 2004;202:496-502.

38 Daridon C, Devauchelle V, Hutin P, et al. Aberrant expression of BAFF by B lymphocytes infiltrating the salivary glands of patients with primary Sjogren's syndrome. Arthritis Rheum 2007;56:1134-1144.

39 Seyler TM, Park YW, Takemura S, et al. BLyS and APRIL in rheumatoid arthritis. J Clin Invest 2005;115:3083-3092.

40 Nagatani K, Itoh K, Nakajima K, et al. Rheumatoid arthritis fibroblast-like synoviocytes express BCMA and are stimulated by APRIL. Arthritis Rheum 2007;56:3554-3563.

41 Ohata J, Zvaifler NJ, Nishio M, et al. Fibroblast-like synoviocytes of mesenchymal origin express functional B cell-activating factor of the TNF family in response to proinflammatory cytokines. J Immunol 2005;174:864-870.

42 Kimberley FC, Hahne M, Medema JP. 'APRIL hath put a spring of youth in everything': Relevance of APRIL for survival. J Cell Physiol 2009;218:1-8.
43 Nishio M, Endo T, Tsukada N, et al. Nurselike cells express BAFF and APRIL, which can promote survival of chronic lymphocytic leukemia cells via a paracrine pathway distinct from that of SDF-1alpha. Blood 2005;106:1012-1020.

44 Kimberley FC, van Bostelen L, Cameron K, et al. The proteoglycan (heparan sulfate proteoglycan) binding domain of APRIL serves as a platform for ligand multimerization and cross-linking. FASEB J 2009;23:1584-1595.

45 Thomas GJ, Mason RM, Davies M. Characterization of proteoglycans synthesized by human adult glomerular mesangial cells in culture. Biochem J 1991;277: 81-88.

46 Hooke DH, Gee DC, Atkins RC. Leukocyte analysis using monoclonal antibodies in human glomerulonephritis. Kidney Int 1987;31:964-972.

47 Alexopoulos E, Seron D, Hartley RB, Cameron JS. Lupus nephritis: correlation of interstitial cells with glomerular function. Kidney Int 1990;37: 100-109.

48 Yoshimoto S, Nakatani K, Iwano M, et al. Elevated levels of fractalkine expression and accumulation of CD16+ monocytes in glomeruli of active lupus nephritis. Am J Kidney Dis 2007;50:47-58. 